\title{
A Very Rare Cause of Localized Nonscarring Alopecia: Nevus Psiloliparus- a case Review
}

\author{
Betul Tas ${ }^{1 *}$, Ugur Izol ${ }^{2}$ \\ ${ }^{1}$ Health Sciences University, Istanbul Bagcilar Training and Research Hospital, Department of \\ Dermatovenereology, Istanbul/Turkey \\ ${ }^{2}$ Health Sciences University, Istanbul Bagcilar Research and Training Hospital, Department of Pathology, \\ Istanbul/Turkey \\ *Corresponding Author: Betul Tas, Health Sciences University, Istanbul Bagcilar Training and \\ Research Hospital, Department of Dermatovenereology, Istanbul/Turkey,Email: betulavc@yahoo.com

\begin{abstract}
One of the rare causes of localized and nonscarring alopecia is nevus psiloliparus (NP) which is a distinct type of mesodermal nevus of the scalp. It is characterized by absence or paucity of mature hair follicles and presence of an excessive amount fatty tissue in the scalp. It is considered a hallmark of encephalocraniocutaneous lipomatosis (ECCL), a rare disorder comprising a variety of cutaneous, ophthalmologic and neurologic defects, but can appear as an isolated finding. We report a rare case of nonsyndromic NP.
\end{abstract}

Keywords: Encephalocraniocutaneous lipomatosis; fatty tissue nevus; nevus psiloliparus; patchy hypotrichosis.

\section{INTRODUCTION}

NP is a very rare lipomatous hamartoma of the scalp. Typically, it is found in as an essential component of ECCL, however, isolated cases have also been reported [1,2]. The lesion may accompany some dermatological signs such as focal dermal hypoplasia, alopecia, periocular skin tag, aplasia cutis congenita, and noncutaneous structures such as desmoid tumors and choristomas of the eye, maxillary odontoma, bone cysts, intracranial or spinal lipomas, intracranial calcification, arachnoid cysts, atrophy of a hemisphere, porencephalic cysts, hydrocephalus, ventricular dilatation, and mental retardation [3-5].

\section{CASE}

A 76-year-old man was admitted to our dermatology clinic due to a scalp swelling which he had been observing for eight years and which kept growing and causing hair loss. In the personal medical history, trauma, surgery or other interventional procedures for this region, chronic drug use, or any other pathologies were absent. Family history revealed no findings for encephalocraniocutaneous syndrome or a similar lesion. Dermatological examination showed a male pattern alopecia (Norwood stageVII) severe seborrheic dermatitis, and a $9,5 \times 7,5 \mathrm{~cm}$ in sizes erythematous and soft alopecic nodule on the left temporoparietal area of the scalp. The alopecic nodule had rare hairs with normal length (Figure 1).

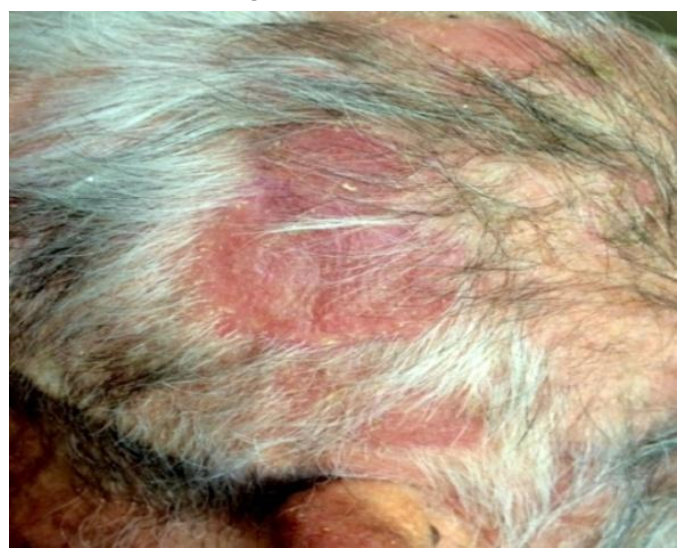

Figure1. Clinical appearance of the hamartoma located on the left temporoparietal area of the scalp

The hair-pull test was negative and the lesion was symptomless. The deepest point of the mass which were measured with a sterile needle was $24 \mathrm{~mm}$. The lesion was biopsied from the deepest part of the mass, and sent for pathological examination. In the histopathological examination, mild epidermal keratinization, mild spongiosis in granular layer, follicular proliferation, nonspecific perivascular infiltration, thinning and fibrosing changes in the dermis, significant increase in subcutaneous fatty tissue, and many prominent and ectopic hyperplasia in erector pili muscles in the subcutis were seen (Figure 2 a, b). 


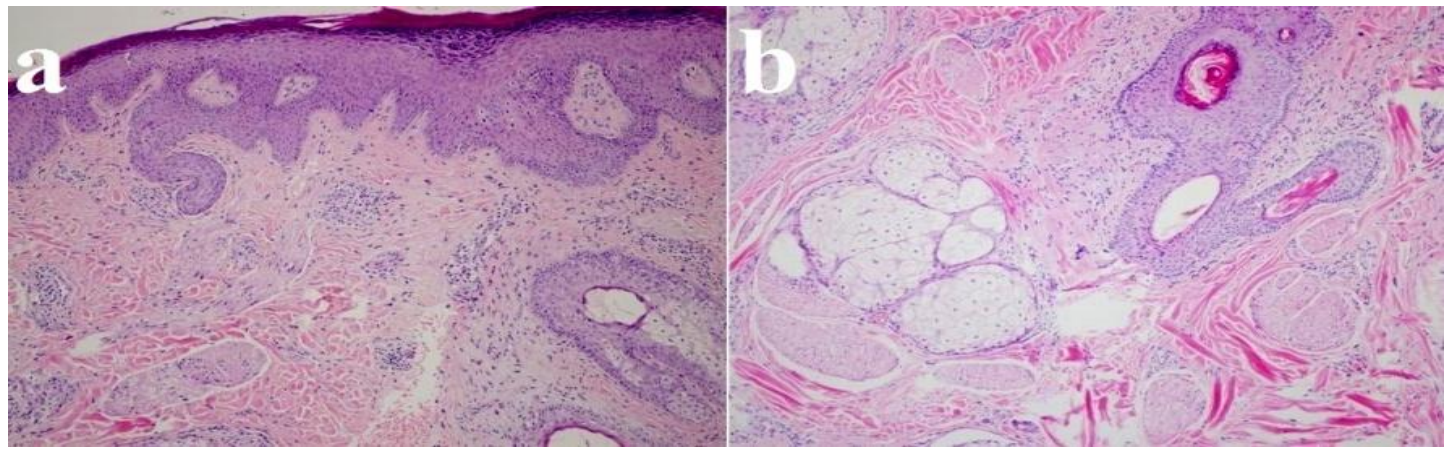

Figure2. a) Absence of mature hair follicles, and orphaned bundles of smooth muscles in the dermis (HE X40). b) A large number of non-cutaneous adnexal erector pili muscles in large quantities of mature subcutaneous fatty tissue (HE X100).

No other pathologies were identified in the dermatological, routine hematological and biochemical examinations. No pathological findings were detected in the neurological and ophthalmologic consultations. Cranio-spinal, thoracic and abdominal MR images and EEG were normal. With the obtained evidence, the lesion was diagnosed with isolated nonsyndromic nevus psiloliparus. The patient was informed about the disease. He did not demand any cosmetic remedy.

\section{DISCUSSION}

Haberland syndrome or ECCL is a rarely occurred neurocutaneous syndrome which was described as an example of ectomesodermal dysgenesis, by Haberland and Perou in 1970 [2,5-9]. The exact mode of inheritance for ECCL is still unknown. However, it is most likely considered that it can be result of an autosomal mosaicism $[5,10]$. On the other hand, NP is a less known mesodermal nevus of the scalp [4] which affects both sexes equally [1-3]. The term "NP" has been stemmed from the combination of Greek words "psilos=hairy" and "liparus=fatty". Until 1997, NP was only considered as a "nameless but pathognomonic" cutaneous scalp component, and the most common cutaneous finding of ECCL. However, nonsyndromic and isolated form of NP, firstly described and specifically named by Happle and Küster, in 1998 [4,8,11]. Chan et al. have stated that, NP lesions were detected in $36(97 \%)$ of previously reported 37 patients with ECCL until $2006[12,13]$. The hamartomatous scalp lesions include hairless or less-hairy, flat or dome shaped, usually skin-colored or yellowish, soft, mostly unilateral, and rarely bilateral masses [1-3, 5]. Sometimes the lesions can be seen in patchy or linear patterns which follow the Blaschko lines [8]. The sizes of the lesions may vary from a few milimeters to a few centimeters [1-3]. In the case of ECCL, a wide range of congenital findings such as coristoma, desmoid tumor of eye, epibulbar or limbal dermolipoma, cornea or sclera abnormality, palpebral coloboma, anterior chamber anomaly, aniridia, microftalmia, maxillar odontoma, bone cysts, cerebral unilateral atrophy, unilateral ventricular dilatation of cerebellum, leptomeningeal angiomatosis, ossifying fibroma, macrocephalia, hypospadias, hydronephrosis, stenosis of audituar canal, premature thelarche, mental retardation with or without convulsion, aortic coarctation, spinal or leptomeningeal lipoma can accompany NP $[3,5,6]$. Simultaneous intraserebral patologies are usually tend to be the same side of the scalp $[2,4,6]$. Diagnosis of NP is made based on the aforementioned clinical features, and typical histopathological findings which are absence of mature hair follicles due to arrested development of pilosebaceous units, isolated or orphaned hyperplasia of erector pili muscles in the dermis, and increase in lipomatous or fibrolipomatous tissue extending into the upper reticular dermis [1-3,5]. In isolated cases of NP, except for the other acquired or congenital reasons for circumscribed hair loss such as alopecia areata (AA), aplasia cutis congenita (ACC) or temporal triangular alopecia (TTA), due to the lipodematous appearance and soft consistency of the masses, especially solitary lipomas of the scalp [1], lipodematous scalp (LS) and lipodematous alopecia (LA) should be considered in differential diagnoses. In AA, which is an autoimmune and acquired condition, presence of exclamation mark hairs and positive hair pull test are important distinguishing findings [14-16]. ACC is another rare scalp anomaly which is usually characterized by a localized, complete or partial absence of skin at birth. It usually appears as well-demarcated, translucent or ulcerated membranes. It may be an isolated lesion or may accompany other congenital abnormalities [4,17]. TTA is rare congenital scalp disease. I is characterized by 
usually sporadic but rarely syndromal, earlyonset, unilateral and well-circumscribed, triangular or lancet-shaped, non-cicatricial hypotrichosis in the frontotemporal area, and usually manifests after 2 years of age. The lesion is distinguished from AA with the typical history, shape and location of the lesion, absence of exclamation mark hairs, negative hair pull test, typical miniaturized vellus hairs with normal density [14-16], and, it can also be distinguished from NP with absence of increased fatty tissue and orphaned hyperplasia of erector pili muscles[1-3,5]. On the other hand, the last two conditions mentioned above (LS and LA) have been considered as distinct entities by some authors, while some others have evaluate that the LA was an advanced form of LS. Hair pull test is negative in NP, but it is positive in especially LA. In the case of LS, when pressed onto the lesion, a temporary depression can be created. Isolated NP is usually symptomless and harmless condition, however in the case of LS or LA, some subjective symptoms such as pruritus, pain or paresthesia can accompany the lesions.

Histopathologically, instead of the presence an increased subcutaneous fatty tissue in NP, a noticeably subcutaneous edema, increased in dermal collagen and dilated lymphatic vessels in the dermis come to the fore in LS and LA, but pilar muscle hypertrophy is absent. The count of the follicules is usually normal in NP, where as it is usually decreased and sometimes associated with a perifollicular fibrosis or focal bulber atrophy, in these two conditions [18,19]. Additionally, increase in the erector pili muscles facilitates distinguishing the lesion from the nevus lipomatosis superficialis $[1,2]$. ECCL or $\mathrm{NP}$ is not progressive conditions. Unless the lesion accompanied by another but serious congenital abnormality, it is usually harmless and does not need any treatment. When patients demand, ablative lasers can provide a temporary benefit, but the most appropriate treatment is surgical excision [2]. However, especially when it is being a component of ECCL, easily and early recognition of NP by clinicians may be life-saving, and can prevent redundant treatments.

\section{REFERENCES}

[1] Ulrich Hohenleutner: Malformations of Vessels, Fat and Connective tissue. Braun Falco's Dermatology. Eds. Burgdorf WHC, Plewig G, Wolff HH, Landthaler M, 3rd edition. Heidelberg, Springer Mediz Verlag, 2009;795-812.
[2] Happle R, Horster S. Nevus psiloliparus: report of two nonsyndromic cases. Eur $\mathrm{J}$ Dermatol. 2004;14(5);314-6.

[3] Moss C, Shahidulla H. : Naevi and other Development Defects. Rook's textbook of Dermatology. Eds. Burns T , Breathnach S, Cox N, Griffiths C. Eighth edition, WestSussex, Wiley\&Blackwell, 2010;18.1-18.107.

[4] Torrelo A, Boente M C, Nieto O, Asial R ,Colmenero I., Winik B et all, Nevus psiloliparus and aplasia cutis: a further possible example of didymosis. Pediatr Dermatol. 2005; 22(3):206-9.

[5] Banta J, Beasley K, Kobayashi T, Rohena L. Encephalocraniocutaneous lipomatosis (Haberland syndrome): A mild case with bilateral cutaneous and ocular involvement. Case Rep. 2016; 2(2): 150-2.

[6] Kodsi SR, Bloom KE, Egbert JE, Holland EJ, Cameron JD.Ocular and systemic manifestations of encephalocraniocutaneous lipomatosis. Am J Ophtalmol. 1994;118:77-82.

[7] Moog U, Roelens F, Mortier GR, Sijstermans H, Kelly M, Cox GF et al. Encephalocraniocutaneous lipomatosis accompanied by the formation of bone cysts: Harboring clues to pathogenesis? Am J Med Genet A. 2007;143A:2973-80.

[8] Moog U. Encephalocraniocutaneous lipomatosis. J Med Genet. 2009;46(11):721-9.

[9] Valladares MJ, Blanco MJ, Lopez-Lopez F, Gonzales F. Bilateral ocular involvement in encephalocraniocutaneous lipomatosis. Eur J Paediatr Neurol. 2007;11:108-10.

[10] Pardo IA, Nicolas ME. A Filipino male with encephalocraniocutaneous lipomatosis (Haberland's syndrome). J Dermatol Case Rep. 2013;7(2):46-8.

[11] Stieler K.M., Astner S., Bohner G. Encephalocraniocutaneous lipomatosis with didymosis aplasticopsilolipara. Arch Dermatol. 2008;144(2):266-8.

[12] Almer Z, Vishnevskia-Dai V, Zadok D. Encephalocraniocutaneous lipomatosis:case report and review of the literature. Cornea. 2003;22(4);389-90.

[13] Chan CC, Chen JS, Chu CY. Haberland syndrome. Dermatol Sinica. 2005;23:41-5.

[14] Trakimas C, Sperling LC. Temporal triangular alopecia acquired in adulthood. J Am Acad Dermatol. 1999;40:842-4.

[15] Gupta LK, Garg A, Mittal A. Congenital triangular alopecia: a close mimicker of alopecia areata. Int J Trichology. 2011;3:40-1.

[16] Ruggieri M, Rizzo R, Happle R. Temporal triangular alopecia in association with mental retardation and epilepsy in a mother and daughter. Arch Dermatol. 2000;136:426-7. 
[17] Brzezinsky B, Pinteala T, Chiriac AE, Foia L, Chiriac A. Aplasia cutis congenita of the scalpwhat are the steps to be followed? Case report and review of the literature. An Bras Dermatol. 2015; 90(1). http://dx.doi.org/10.1590/abd18 06-4841.20153078.

[18] Loffreda MD, Inflamatuar diseases of hair follicles sweat glands and cartilage. Lever's histopathology of the skin . Ed.Elder E David. 10th edition. Philadelphia . Wolters Kluwer \&Lippincott Williams-Wilkins. 2009;18:459501.

[19] 19. Martinez- Moran C., Sanz-Munoz C., Miranda -Sivelo A., Torne I, Miranda Romero A, Lipedematous scalp. Actas Dermosifiliogr. 2009;100(1):69-72.

Citation: Betul Tas, Ugur Izol. A Very Rare Cause of Localized Nonscarring Alopecia: Nevus Psiloliparus- a case Review. ARC Journal of Dermatology. 2017; 2(2): 18-21. doi:dx.doi.org/10.20431/2456-0022.0202005.

Copyright: (C) 2017 Authors. This is an open-access article distributed under the terms of the Creative Commons Attribution License, which permits unrestricted use, distribution, and reproduction in any medium, provided the original author and source are credited. 